\title{
A Fabricação do Patrimônio Cultural ${ }^{1}$ The Making of Cultural Heritage
}

\author{
HEINICH, Nathalie. The Making of Cultural Heritage. The Nordic Journal of Aesthetics,
} Aarhus, n. 40-41, p. 119-128, 2010-2011. DOI: https://doi.org/10.7146/nja.v22i40-41.5203.

\section{Nathalie Heinich ${ }^{2}$ \\ Tradução: Diego Finder Machado ${ }^{3}$ Fernando Cesar Sossai ${ }^{4}$}

\begin{abstract}
Resumo: Como um artefato adentra o conjunto do patrimônio cultural nacional? A resposta a essa questão oferece uma compreensão pragmática das razões pelas quais a expansão dos conjuntos patrimoniais nacionais tem sido tão difundida, geração após geração e especialmente durante a última. Por certo, há também razões "sociais" ou "culturais" mais gerais para tal fenômeno mundial: várias explicações já foram propostas por filósofos, historiadores, sociólogos e antropólogos. No entanto, não se deve subestimar os efeitos das técnicas inventariais e dos métodos de descrição utilizados pelos especialistas do patrimônio, na medida em que tendem a elevar o nível de precisão e de especialização, expandindo os critérios e aumentando o número de artefatos que integram seu conjunto. Um estudo aprofundado desses critérios vigentes, por meio de uma pesquisa realizada de acordo com o que hoje é chamado na França de "sociologia pragmática", nos permite uma compreensão mais aprofundada daquilo que define o patrimônio cultural e os valores efetivos nos quais ele se baseia: isso é, a axiologia do patrimônio cultural. Mudar do "por que" para o "como" abre, assim, uma visão renovada dos significados do patrimônio cultural.
\end{abstract}

Palavras-chave: Sociologia das Artes; Patrimônio Cultural; Preservação; Valores Culturais; Função Patrimonial.

\begin{abstract}
How does an artefact enter the corpus of national cultural heritage? The answer to this question offers a pragmatic understanding of the reasons why the expansion of national corpuses has been so widespread, generation after generation and especially during the last one. Of course, there are also more general "societal" or "cultural" reasons for such a worldwide phenomenon: a number of explanations have already been proposed by philosophers, historians, sociologists, anthropologists. However, one should not underestimate the effects of the inventorial techniques and methods of description used by the specialists of heritage, in that they tend to elevate the level of precision and of specialisation, hence to enlarge the criteria and to increase the number of artefacts worth entering their corpus. A close study of these actual criteria, through a survey conducted according to what is now called "pragmatic sociology" in France, allows us a deeper understanding of what defines cultural heritage, and of the effective values on which it relies: that is, the axiology of cultural heritage. Switching from "why" to "how" thus opens up for renewed insight into the meanings of cultural heritage.
\end{abstract}

Keywords: Sociology of the Arts; Cultural Heritage; Preservation; Cultural Values; Patrimonial Function.

\footnotetext{
${ }^{1}$ Agradecemos à autora do texto, Nathalie Heinich, e ao editor-chefe do The Nordic Journal of Aesthetics, Jacob Lund, por autorizarem a publicação do texto, traduzido pela primeira vez para a língua portuguesa, na Fronteiras: Revista Catarinense de História.

${ }^{2}$ Socióloga e diretora de pesquisa junto ao Centro Nacional de Pesquisa Científica (CNRS, Paris), associada ao Centro de Pesquisa sobre as Artes e a Linguagem (CRAL) na Escola de Altos Estudos em Ciências Sociais (EHESS). Suas pesquisas abordam a sociologia das artes (profissões artísticas, percepção estética e conflitos em torno da arte contemporânea), a socio-antropologia da crise das identidades (na ficção, em testemunhos autorais ou de sobreviventes e na identidade feminina), a sociologia dos valores (nas artes e no patrimônio cultural) e a epistemologia das ciências sociais. E-mail: nathalie.heinich@ehess.fr.

${ }^{3}$ Bolsista do Programa Nacional de Pós-Doutorado da Coordenação de Aperfeiçoamento de Pessoal de Nível Superior (PNPD/Capes), junto ao Programa de Pós-Graduação em Patrimônio Cultural e Sociedade da Universidade da Região de Joinville (UNIVILLE). Integra o Grupo de Pesquisa "Cidade Cultura e Diferença”. Email: diego_finder@yahoo.com.br

${ }^{4}$ Docente do curso de História e do Programa de Programa de Pós-Graduação em Patrimônio Cultural e Sociedade da UNIVILLE. Vice-líder do Grupo de Pesquisa "Cidade Cultura e Diferença". E-mail: fernandosossai@gmail.com
} 
Quando iniciei minha pesquisa sobre a fabricação do patrimônio cultural nacional na França, há alguns anos, pensei que estaria trabalhando principalmente na estética de um novo campo, o que me permitiria ampliar e desenvolver minhas investigações sobre a sociologia das artes. No entanto, surpreendentemente, descobri que a estética era apenas marginal nesse contexto. Também achei que tinha a ver com o meio ambiente, uma vez que o patrimônio em jogo - patrimoine, como chamamos na França - diz respeito a artefatos in situ, especialmente edificações, incluindo sua relação com os seus locais. Mas o que descobri foi de algum modo perturbador à luz dessas expectativas: a arte e a estética parecem ser questões muito marginais para os especialistas do patrimônio, enquanto outros valores parecem ser muito mais relevantes - alguns deles também centrais em questões ambientais. Esse é o tópico deste artigo.

Sem dúvida, este artigo irá desapontar aqueles que esperam grandes resultados teóricos que costumam aparecer em um congresso de sociologia como "cultura", "identidade nacional", "pós-modernismo" ou "o social", todas noções geralmente mitificadas por uma concepção metafísica da sociologia em busca de um princípio transcendental. Tampouco pretenderei demonstrar que o patrimônio não é uma essência, mas um fenômeno "socialmente construído" (que, para qualquer sociólogo, nunca deve ser um resultado final, mas apenas um ponto de partida óbvio a partir do qual pode explorar como um fenômeno é criado, transformado e sustentado por humanos). Não. Eu irei simplesmente tentar descrever um tipo particular de experiência, isso é, a experiência patrimonial, do ponto de vista dos valores que ela implementa, e com os métodos da sociologia dos valores empírica, pragmática e isenta de juízos de valor que eu atualmente estou desenvolvendo.

Contudo, irei abordar essa experiência patrimonial não através dos olhos daqueles que visitam monumentos ou admiram pinturas antigas penduradas em igrejas, mas pelos olhos daqueles que "fazem" o patrimônio: isso é, os historiadores da arte profissionais nomeados pelo Ministério da Cultura para decidir se um edifício ou um objeto deve ou não ser incluído no conjunto do patrimônio nacional. Na França, eles pertencem a uma administração especial criada durante a década de 1960, chamada Inventaire Général (Serviço do Inventário Geral). Presumo que a maioria dos países europeus possua serviços similares.

Antes de descrever os critérios e os sistemas de valores utilizados pelos especialistas que decidem se um artefato merece ser considerado parte do patrimônio nacional, devo dizer 
algumas palavras sobre o crescimento vertiginoso do conjunto patrimonial e algumas de suas possíveis razões.

\section{O crescimento vertiginoso do patrimônio cultural nacional e algumas de suas possíveis razões}

O conjunto do patrimônio nacional tem sido dramaticamente ampliado, geração após geração, especialmente durante a última. Na França, mais de 43.000 monumentos estavam protegidos como parte dos "Monumentos Históricos" em 2007, e cerca de 140 são "classificados" como tais todos os anos, enquanto de 1836 a 1840, durante os primeiros anos seguintes à criação dessa administração, apenas 13 haviam sido classificados. Esse fenômeno não é especificamente francês, obviamente, nem é especificamente europeu: no decurso do século XX, a proteção dos "monumentos históricos" ou do "patrimônio nacional" revelou-se ainda mais necessária a nível internacional.

Provavelmente, existem algumas razões sociais ou culturais gerais para tal fenômeno mundial: várias explicações já foram propostas por filósofos, historiadores, sociólogos e antropólogos. Alguns historiadores, por exemplo, explicaram o surgimento da própria noção de monumento histórico na França como uma reação às destruições revolucionárias. Quanto aos sociólogos, uma hipótese semelhante apareceu na década de 1980, junto à última grande onda patrimonial: o interesse pelo patrimônio cresceria com as destruições, não mais devido à violência revolucionária, mas à modernização industrial, especialmente após a Segunda Guerra Mundial. Citemos também o antropólogo francês Maurice Godelier. Segundo ele, toda sociedade distingue três categorias de coisas: as que são vendidas, as que são dadas e as que são mantidas. Então, o culto moderno do patrimônio resultaria de uma transferência de sacralidade: artefatos patrimoniais tomariam o lugar dos "tesouros" anteriores, sejam eles religiosos ou régios, no sistema simbólico das sociedades modernas confrontadas com o "processo de desencantamento".

Mas ao invés de tentar explicar as causas de nossa inflação patrimonial, meu objetivo é descrever e entender suas modalidades a partir de seu interior. Nessa perspectiva, o "como" substituirá o "por que" e a sociologia compreensiva substituirá a sociologia explicativa.

\section{As ações dos encarregados de "fazer" o patrimônio?}


A que se referem as ações dos encarregados de "fazer" o patrimônio? Isso é, a seleção de um artefato para incluí-lo em um conjunto patrimonial?

A meu ver, as técnicas inventariais e os métodos de descrição utilizados pelos especialistas do patrimônio tendem a se tornar cada vez mais precisos e especializados, expandindo os critérios de seleção e, assim, aumentando o número de artefatos que valem a pena entrar em seu conjunto.

Minha pesquisa a respeito da administração francesa do patrimônio, conduzida em 2004 de acordo com os métodos etnográficos, ajuda a abordar essa questão sob uma perspectiva renovada, fundamentada na observação atenta de ações dentro de um contexto preciso: o que hoje chamamos de "sociologia pragmática", baseada em observações de situações concretas, enfocando as ações dos atores. Quero enfatizar que, na minha perspectiva, essa abordagem metodológica não se refere muito à filosofia "pragmática", mas ao "pragmatismo" linguístico, que enfoca mais os usos efetivos e concretos da linguagem em vez de seus princípios abstratos. A abordagem pragmática considera tanto os objetos quanto os sujeitos em termos de suas ações, em vez de tratá-los como suportes passivos de projeções - sejam projeções de categorias sociais ou de representações coletivas etc.

Usando esse método pragmático, eu acompanhei numerosos especialistas "em campo" (sur le terrain), quando eles estavam no processo de observar todos os edifícios em uma determinada área, a fim de decidir quais valeriam a pena listar, descrever, selecionar ou, talvez, estudar. Solicitei a eles que explicassem os problemas que encontravam e os critérios que utilizavam. Cerca de quarenta horas de entrevistas foram coletadas, acompanhadas de várias fotografias e de documentos. As entrevistas foram submetidas a uma análise temática. Os resultados foram publicados em vários artigos e, finalmente, em um livro, La Fabrique du patrimoine.

\section{Os critérios efetivamente utilizados}

Como resultado dessa pesquisa, pude esclarecer os critérios efetivamente utilizados pelos especialistas do patrimônio e confrontá-los com as normas que eles devem implementar em seu trabalho. 
Esses critérios dependem de uma quantidade daquilo que James Gibson tem chamado de affordances $^{5}$ (por exemplo, a forma de uma janela). Quanto aos critérios (por exemplo: a data do edifício), alguns deles são oficialmente prescritos (isso é, listados no guia metodológico editado pela direção dessa administração), enquanto outros não, por serem considerados marginais ou muito problemáticos. Em outro nível, alguns deles são unívocos (são sempre positivos, em qualquer contexto: é o caso da antiguidade), enquanto alguns deles são ambivalentes (podem ser positivos ou negativos dependendo do contexto: por exemplo, a raridade).

Quatro categorias de critérios poderiam ser listadas, comparando suas proximidades às normas ou prescrições "oficiais", por um lado, e sua vulnerabilidade às variações contextuais, de outro. O primeiro eixo opõe, portanto, critérios prescritos e não autorizados. O segundo eixo, por sua vez, opõe critérios unívocos e ambivalentes. Ao cruzar esses dois eixos, obtemos quatro categorias principais de critérios:

(1) critérios prescritos e unívocos (principalmente, estado de conservação e época);

(2) critérios prescritos e ambivalentes (principalmente, raridade de itens similares);

(3) critérios latentes (por exemplo, a acessibilidade material de uma edificação);

(4) um critério proscrito: a beleza, por ser considerado subjetivo demais para sustentar um tratamento científico do conjunto do patrimônio. No entanto, palavras pertencentes ao vocabulário estético ("bonito", "feio" e assim por diante) por vezes apareciam nos comentários dos pesquisadores que eu observava, mas sempre com voz baixa ou com risos, traindo o status ilegítimo de tal critério nesse contexto.

Cerca de vinte critérios foram elencados por meio dessa pesquisa, pertencentes a essas quatro categorias. Este foi o primeiro passo da análise. Não vou desenvolver essa lista de critérios aqui, porque quero insistir no próximo passo, ou seja, nos valores subjacentes a esses critérios. Por "valores", quero dizer simplesmente os princípios que regem os juízos de valor.

\section{Valores fundamentais subjacentes}

\footnotetext{
${ }^{5}$ N. T.: O termo affordance, cunhado pelo psicólogo James J. Gibson, diz respeito ao potencial de um objeto de ser usado tal como foi projetado para ser usado.
} 
O segundo passo revelou um pequeno número de valores fundamentais como subjacentes a esses critérios. Esses cinco valores básicos são:

(1) o valor de autenticidade, referindo-se à integridade do vínculo entre o estado atual do objeto e sua origem. Esse valor é uma condição absoluta, presente em qualquer caso: pode ser considerado o próprio âmago do patrimônio;

(2) o valor de antiguidade, referindo-se à duração do vínculo com a origem: absolutamente relevante a uma concepção mais tradicional ou de senso comum, relativamente relevante a uma concepção mais científica;

(3) o valor de raridade, referindo-se ao pequeno número de itens existentes em uma mesma categoria: mais relevante a uma concepção tradicional ou de senso comum, enquanto a abordagem científica pode valorizar um item por seu pertencimento a uma série;

(4) o valor de beleza, qualquer que seja o seu critério: harmonia, simetria, elegância, adornos sofisticados etc. (relevante a uma concepção tradicional ou de senso comum); ou tipicidade, perfeita correspondência com as propriedades da categoria (relevante a uma abordagem científica);

(5) o valor de significação, referindo-se à capacidade de transmitir um significado, de simbolizar algo, de aceitar comentários, interpretações, etc.: mais relevante a uma abordagem científica.

Exceto pelo valor de autenticidade, que está sempre presente, esses valores variam de acordo com as diferentes concepções de patrimônio: entre a concepção tradicional ou de senso comum, em um extremo da cadeia, e a concepção mais científica, no outro extremo - sendo esta, o próprio escopo da minha pesquisa.

\section{Famílias de valores}

O terceiro passo da análise mostrou como esses cinco valores podem estar relacionados a "registros de valores" mais gerais - ou seja, famílias de valores mais gerais, os quais são relevantes em muitos outros contextos da vida social: da arte contemporânea à tourada, da política à vida científica, da religião ao esporte. De várias pesquisas que venho desenvolvendo a respeito de diversas situações de juízo de valor, o conjunto de numerosos "registros de 
valores" foi estabelecido até hoje: éticos, estéticos, estésicos, hermenêuticos, cívicos, jurídicos, econômicos, domésticos, funcionais, reputacionais, purificadores.

Quanto à questão do patrimônio nacional, o repertório de registros de valores permitenos referir o valor da antiguidade ao registro denominado "doméstico", seguindo aqui o modelo dos tópicos de "justificação" explicado por dois sociólogos franceses, Luc Boltanski e Laurent Thévenot. De acordo com esse modelo, o registro "doméstico" promove o respeito pelos idosos, o pertencimento familiar, a confiança, o cuidado com a transmissão. Todos esses requisitos estão obviamente presentes na própria noção de patrimônio, seja ele familiar ou nacional.

Quanto ao valor da autenticidade, ele pertence ao que denomino de registro "purificador", referente a todos os valores de integridade e, em particular, a integridade do vínculo com as origens - uma razão pela qual se inclui também a autenticidade como higiene ou ecologia. Aqui está uma forte ligação entre patrimônio e meio ambiente: ambos dependem de uma exigência de pureza, o que pode resultar, também, no valor de autenticidade como valor do "ecologicamente correto".

Quanto ao valor de significação, ele pertence ao registro "hermenêutico", fomentando a busca por um significado, atividade interpretativa e simbólica. É central na abordagem mais científica do patrimônio - aquela dos especialistas do Inventaire que observei -, ao passo que parece ser substituída pelo valor de beleza por um relacionamento menos especializado e mais de senso comum ou profano com o patrimônio.

Esse valor de beleza pertence ao registro "estético", lidando com as noções de arte e de beleza. É essencial aqui notar que esse registro está longe de ser o principal que rege a relação com o patrimônio. Em particular, seria fortemente enganoso confundir esse registro estético com o registro purificador ou com o registro hermenêutico: a exigência de autenticidade ou de significado não implica necessariamente uma exigência de beleza. A arte contemporânea, como tentei descrever em minha pesquisa anterior, é um exemplo óbvio da necessária distinção entre beleza, autenticidade e significado. O patrimônio é outro caso.

E sobre o valor da raridade o qual mencionei anteriormente? Não pertence a nenhum "registro de valores", mas a outro tipo de categoria mais geral, que proponho chamar de "regime de valores", como explicarei agora.

\section{Os dois regimes de valores}


$\mathrm{Na}$ quarta e última etapa da análise, dois "regimes de valores" foram discernidos, em um nível muito geral. Esse alto nível de generalidade permite comparações com outros sistemas de valores em diferentes contextos. Os dois regimes são o "regime de singularidade" e o "regime de comunidade".

Para compreender o que eles significam, voltemos ao valor de raridade. Você deve ter notado que eu não relacionei esse valor com os "registros de valores" que acabei de mencionar. A razão disso é que a raridade possui um status especial. É um valor ambivalente, uma vez que pode ser positivo ou negativo: positivo de acordo com a concepção tradicional do patrimônio, centrando-se em algumas obras-primas; mas negativo de acordo com uma abordagem mais científica, tentando discernir séries e tipos, construir tipologias e produzir estatísticas. Mais especificamente, o valor de raridade não está em um mesmo nível que os outros: é um índice, uma marca concedida a qualquer valor, seja negativamente ou positivamente. Por exemplo, a beleza pode ser definida por conformidade com as regras aceitas (regime de comunidade) ou, ao contrário, pela originalidade (regime de singularidade); a autenticidade pode ser encontrada em séries (regime de comunidade) ou individualmente (regime de singularidade); a significação pode ser valorizada na medida em que é acessível a todos (regime de comunidade) ou, ao contrário, na medida em que é esotérica (regime de singularidade).

É por isso que a raridade, juntamente com o seu contrário, a multiplicidade, é o que poderíamos chamar de "valores ortogonais", que englobam todos os outros, seja para reforçálos, seja para enfraquecê-los. Assim, eles pertencem a uma ordem mais geral do que os "registros de valores": o que eu chamo de "regime" de qualificação - qualificação significando tanto definição quanto valorização. Nessa perspectiva, o "regime de singularidade" valoriza tudo o que é raro, fora do comum, único; enquanto seu oposto, o "regime de comunidade", valoriza o múltiplo, o padrão, o convencional. Notemos que a noção de monumento está fortemente ligada ao "regime de singularidade" (já que seu padrão é a obra prima, o artefato excepcional), enquanto a noção de patrimônio pertence ao "regime de comunidade" (já que pertence a uma comunidade). Esse duplo status axiológico do patrimônio nacional é provavelmente uma das razões pelas quais tal questão é tão rica e poderosa, tanto para os sociólogos quanto para os atores: ela pode satisfazer as expectativas tanto de singularidade quanto de comunidade.

Toda essa configuração de affordances, critérios, valores, registros de valores e regimes de valores constituem o que poderia ser chamado de "axiologia do patrimônio cultural": em outras palavras, o sistema de valores próprio desse domínio muito especial de nossa cultura 
comum. Aqui, um novo caminho se abre à sociologia dos valores que estou propondo - uma sociologia não-essencialista, pragmática, empírica e axiologicamente neutra, como anunciado em minha introdução.

E aqui emerge uma possível resposta à pergunta que eu levantei no início do meu artigo: A principal razão pela qual o conjunto do patrimônio nacional cresceu tão rapidamente durante a última geração provavelmente não se encontra em questões de identidade, cultura, sociedade pós-moderna ou algo parecido: em vez disso, a razão está na introdução de métodos mais científicos de seleção na administração da cultura, que tendem a minimizar o lugar da beleza enquanto estendem as fronteiras da antiguidade, promovem o valor de significação e adicionam o valor de tipicidade ao valor mais tradicional de raridade.

Permitam-me concluir com uma última observação sobre a definição de patrimônio. Depois de observar como o patrimônio nacional é produzido por seus especialistas, pode-se fazer a seguinte pergunta: o que é, afinal de contas, um objeto patrimonial?

\section{Do patrimônio à "função patrimonial"}

Sem dúvida, você terá compreendido que não estou tentando dar qualquer tipo de definição ontológica a priori de patrimônio. De acordo com a virada nominalista, o que está em jogo aqui é entender o que os atores querem dizer quando usam esse termo, ou quando agem de modo a conferir tal qualificação a um objeto. É por isso que, em vez de "patrimônio" prefiro falar de "função patrimonial", assim como Michel Foucault falou de "função autor", ou como eu mesmo falei de "função pessoa" quando me referi a algumas categorias de objetos caracterizados por serem insubstituíveis - sejam eles relíquias, fetiches ou obras de arte. Nessa perspectiva, o patrimônio aparece como nada mais do que o estado peculiar resultante de alguns objetos submetidos a certos tipos de operações, através de gestos, escritos, palavras, leis, trocas financeiras etc. Esses objetos podem ser artefatos (como no caso dos monumentos históricos) ou objetos naturais (como no caso dos sítios ou paisagens); eles podem até ser imateriais, de acordo com a nova categoria de "patrimônio imaterial" da UNESCO.

De acordo com essa perspectiva, a função patrimonial pode ser definida como todo o conjunto de ações destinadas a conservar objetos que satisfaçam a uma dupla condição: primeiro, a condição de pertencer à comunidade, sendo considerados como um bem comum (mesmo que permaneçam uma propriedade privada em nível jurídico); e, segundo, a condição de que seu valor durará para sempre. Esse valor eterno origina-se de quatro princípios 
axiológicos básicos, ou seja, quatro valores: autenticidade (referente ao registro purificador), antiguidade (pertencente ao registro doméstico), significação (pertencente ao registro hermenêutico) e beleza (pertencente ao registro estético). Esses quatro valores podem ser mais ou menos aprimorados por um quinto: raridade (referente ao regime de singularidade).

A primeira dessas duas condições - pertencente à comunidade - está ligada a uma grandeza espacial na medida em que amplia o número dos seres envolvidos. Sem essa condição, nada distinguiria um artefato patrimonial de um simples bem familiar, como a foto da minha sala de estar. Quanto à segunda condição - valor eterno - ela está ligada a uma grandeza relacionada ao tempo, na medida em que prolonga a duração. Sem essa condição, nada distinguiria o artefato patrimonial de um simples bem comum, como um sinal de trânsito ou um poste telefônico.

Portanto, a função patrimonial permite que um objeto passe do estado de bem privado para o de "bem comum", como definido por economistas: isso é, evitando tanto a exclusão - já que seu consumo está aberto a todos - como a rivalidade - já que esse consumo não diminui sua quantidade disponível. O objeto patrimonial, portanto, escapa ao destino de se tornar lixo, como descrito por Michael Thompson, bem como o de ser uma mera "coisa", redutível à sua materialidade e à sua utilidade. Pode então tornar-se o que o historiador Krystof Pomian chamou de "semióforo", investido de significados, ou mesmo uma "relíquia" ou um "objeto sagrado": que não pode ser vendido nem dado, mas apenas conservado, como na tipologia de Godelier.

Em outras palavras, o status de patrimônio nacional é o mesmo que o status estético, já que ambos são definidos não por uma propriedade substancial, mas por uma propriedade relacional. Como o especialista em estética francês Gérard Genette afirmou com precisão: "Não é o objeto que faz a relação estética, mas é a relação que faz o objeto estético". Da mesma forma, não é o objeto que faz patrimônio, mas é a função patrimonial que faz de um objeto um bem patrimonial.

Finalmente, como deveríamos chamar o processo por meio do qual qualificações préexistentes são atribuídas a alguns objetos, de modo que acabam anexados a esses objetos e pareçam ser parte deles, definindo sua natureza própria? O que está em jogo aqui não é “descobrir" o valor do objeto (já que o objeto não "contém" esse valor, ele não o possui), nem “inventá-lo" do nada, como se tivesse sido arbitrariamente atribuído (desde que o objeto mais ou menos promova ou permita esta ou aquela qualificação). Em vez disso, digamos que o valor é "administrado" ao objeto: isso é, proposto, então anexado a ele, de uma maneira mais ou 
menos eficiente e duradoura, de acordo com a capacidade do objeto de aceitar tal qualificação. Podemos então concluir que a missão da administração patrimonial - que dizer, o departamento do Ministério da Cultura encarregado dos monumentos históricos - é de fato "administrar" (ou seja, cuidar) os artefatos patrimoniais que foram listados por especialistas. Mas sua missão é também "administrar" (quer dizer, atribuir) o valor de autenticidade aos objetos que serão listados. É por isso que o departamento encarregado dos monumentos históricos pode ser definido, no duplo sentido do termo, como a "administração da autenticidade".

Administrar a autenticidade: essas duas palavras resumem, em conclusão, o que está em jogo no patrimônio cultural nacional. Eu vou deixar vocês decidirem se elas também descrevem adequadamente o que está em jogo no meio ambiente.

\section{Referências Bibliográficas}

BOLTANSKI, Luc; THEVENOT, Laurent. De la justification: Les économies de la grandeur. Paris: Gallimard, 1991.

BORTOLOTTO, Chiara. From Objects to Processes: UNESCO's Intangible Cultural Heritage. Journal of Museum Ethnography, Hull, n. 19, p. 21-33, 2007.

CHASTEL, André. L'Inventaire général des monuments et des richesses artistiques de la France. Revue de l'art, Paris, n. 65, 1984.

DEBRAY, Régis (ed.). L'Abus monumental: Entretiens du patrimoine. Paris: Fayard-Editions du Patrimoine, 1999.

FABRE, Daniel (ed.). Domestiquer l'histoire: Ethnologie des monuments historiques. Paris: Editions de la Maison des sciences de l'homme, 2000.

FOUCAULT, Michel. Qu'est-ce qu'un auteur? Bulletin de la société française de philosophie, Paris, v. 63, n. 3, 1969.

GENETTE, Gérard. L'Oeuvre de l'art. 2. La Relation esthétique. Paris: Seuil, 1997.

GIBSON, James J. The Ecological Approach to Visual Perception. Boston: Houghton Mifflin, 1979.

GODELIER, Maurice. L'Énigme du don. Paris: Fayard, 1996.

HEINICH, Nathalie. Is there a Scientific Beauty? From Factual Description to Aesthetic Judgements. Bezalel. Proceedings of History and Theory, Jerusalem, n. 3, 2006.

La Fabrique du patrimoine: De la cathédrale à la petite cuillère. Paris: Éditions de la Maison des Sciences de l'Homme, 2009. 
Le Triple jeu de l'art contemporain: Sociologie des arts plastiques. Paris: Minuit, 1998. 6, 1993.

Les objets-personnes: fétiches, reliques et oeuvres d'art". Sociologie de l'art, Paris, $\mathrm{n}$.

The Glory of Van Gogh: An Anthropology of Admiration. Princeton: Princeton University Press, 1996.

MELOT, Michel. L'Inventaire général et l'évolution de la notion de patrimoine culturel. In: BARRERE, Christian et. al. (eds.). Réinventer le patrimoine: De la culture à l'économie, une nouvelle pensée du patrimoine? Paris: L'Harmattan, 2005.

NORA, Pierre, ed. Science et conscience du patrimoine: Entretiens du patrimoine. Paris: Fayard-Editions du Patrimoine, 1997.

RIEGL, Aloïs. Le Culte moderne des monuments: Son essence et sa genèse. Paris: Seuil, 1984.

THOMPSON, Michael. Rubbish Theory: The Creation and Destruction of Value. Oxford: Oxford University Press, 1979.

Texto traduzido por: Diego Finder Machado e Fernando Cesar Sossai. 